\title{
Generative Models for Relief Perspective Architectures
}

\author{
Leonardo Baglioni ${ }^{1}\left[\mathbb{C} \cdot\right.$ Federico Fallavollita ${ }^{2}$
}

Accepted: 12 June 2021 / Published online: 22 July 2021

(C) The Author(s) 2021

\begin{abstract}
The present essay investigates the potential of generative representation applied to the study of relief perspective architectures realized in Italy between the sixteenth and seventeenth centuries. In arts, and architecture in particular, relief perspective is a three-dimensional structure able to create the illusion of great depths in small spaces. A method of investigation applied to the case study of the Avila Chapel in Santa Maria in Trastevere in Rome (Antonio Gherardi 1678) is proposed. The research methodology can be extended to other cases and is based on the use of a Relief Perspective Camera, which can create both a linear perspective and a relief perspective. Experimenting mechanically and automatically the perspective transformations from the affine space to the illusory space and vice versa has allowed us to see the case study in a different light.
\end{abstract}

Keywords Relief perspective camera Relief perspective $\cdot$ Linear perspective . Perspective reconstruction · Avila chapel · Antonio Gherardi · Digital representation

\section{Introduction}

Digital representation is a consolidated tool that has stood alongside the traditional graphic tools used by architects and designers for many years. What is today defined by many authors as 'algorithmic representation' is the overcoming of the concept of traditional drawing intended as an "additive process, in which complexity is achieved by the addition and overlap of independent signs traced on paper ... The drawing is not a smart medium, but rather, a code based on standards

Federico Fallavollita

federico.fallavollita@unibo.it

Leonardo Baglioni

leonardo.baglioni@uniroma1.it

1 Department of History, Representation and Restoration of Architecture, Sapienza University of Rome, Piazza Borghese 9, 00186 Rome, Italy

2 Department of Architecture, Alma Mater Studiorum University of Bologna, Viale del Risorgimento 2, 40136 Bologna, Italy 


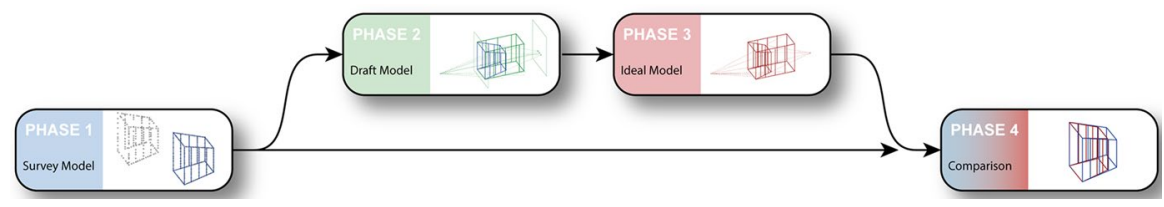

Fig. 1 The methodology structure and its phases

and conventions" (Tedeschi 2014: 16-20). Instead, digital drawing introduces 'associative logics' between the represented objects and the final shape is the result of complex relationships between parameters. The associative character of generative representation finds application not only in the design phase but defines new potentials in the analysis of the constructed shapes.

In this essay we describe a methodology based on the potential of generative representation for studying relief perspectives realized in Italy between the sixteenth and seventeenth centuries. This methodology is based on the idea of a 'virtual laboratory' where we can analyse and experiment the effects of relief perspective in its architectural applications. ${ }^{1}$

'Relief perspective' is known to be a generalization of linear perspective in the field of descriptive geometry. In arts, and architecture in particular, relief perspective is a three-dimensional structure able to create the illusion of great depths in small spaces. The three-dimensional perspective is the result of the harmonious fusion of architecture, painting and sculpture, which in Italian Baroque opens up new aesthetic perceptions to the observer. Our methodology uses digital models for different phases of the research: data collection, experimental analysis of three-dimensional characters and dissemination of results. Three-dimensional digital modelling was used to study design principles for three main reasons: to represent the acquired data graphically by means of 3D laser scanning and digital photogrammetry; to suggest critical reinterpretation of the shapes and the perspective system; to visualize and virtually experiment perspective mechanisms. This methodology (Fig. 1) is structured according to the following four phases:

1. the survey model, phase one: acquisition of morphological metric data by means of 3D laser scanning and digital photogrammetry. Subsequent elaboration of a survey model which is a mathematical representation of the current state of the architectural object;

2. the projection transformation, phase two: construction of the draft model of the illusory architecture conceived by the architect obtained from the transformation of the survey model through the Relief Perspective Camera (RPC);

\footnotetext{
1 The present essay extends a preliminary study on the Avila Chapel presented by authors at the AFGS 2017 conference ( $11^{\text {th }}$ Asian Forum on Graphic Science) held in Tokyo in 2017 and published in the book of abstracts.
} 
3. the ideal model, phase three: construction of the ideal model of the illusory architecture conceived by the architect and based on the proportions and interpretation of the survey model transformed by the RPC;

4. the comparison, phase four: transformation of the ideal model through the RPC and comparison with the survey model.

The principal digital tool is a Relief Perspective Camera (RPC), which is a digital camera able to create linear and relief perspectives. The RPC was designed by generative digital representation. ${ }^{2}$ The RPC is used to study in real time the relations between the projective space and the affine space and vice-versa. Thus, we can apply inverse transformations to the survey model in order to determine the ideal position of the projection centre, the point from which the perspective illusion is most effective.

\section{Historical Framework}

The term 'relief perspective' (also known as solid perspective or accelerated perspective) was introduced after the establishment of projective geometry (Leopold 2019: 241-242) with the studies about projective relationship between figures and spatial systems described by Jean-Victor Poncelet in his Traité des propriétés projectives des Figures (1822). Some years later, in the treatises of Fiedler (1874) and Aschieri (1887), relief perspective represents a generalization of linear perspective and, hence, of representation methods. The theoretical principles can be found in 1600, in Guidobaldo del Monte's work with his treatise Perspectivae Libri Sex (Del Monte 1600), in which the concept of punctum concursus (vanishing point) is introduced for the first time. Guidobaldo controls the projective transformations of space by reducing the relief perspective to a set of linear perspectives in relation to each other and regulated through the theory of points of concurrence (Baglioni and Salvatore 2018: 41-52). The historical figure who marked the passage between ars pingendi and scientia aedificandi is Donato Bramante (Camerota 2001; Andersen 2007). He first appeared in the world of architecture through a work that became the foundation of the developments of stage and illusory architecture: the false choir of Santa Maria at San Satiro in Milan (1479-1482). The relationship between relief perspective and architecture is most evident in theatre space (Steadman 2020) where compositional elements, views, perspectives, machines, scenes, and lighting can be found. In the seventeenth century, the profane theatre in Rome presented very contradictory aspects due to prohibitions and censures. However, in the Eternal City, stage representations and perspective knowledge, understood as discipline and practice, reached an exceptional level.

\footnotetext{
2 The RPC is an algorithm created in Grasshopper. The main 3d modelling software we used for this study are: Rhinoceros, Grasshopper and Cinema 4D.
} 
Fig. 2 The original project by Antonio Gherardi for the Avila Chapel. Drawing, pen and brown ink, brown-gray wash, black chalk support: white laid paper toned for transfer verso; $29.5 \times 17.8 \mathrm{~cm}$. Image: (C) Cooper Hewitt, Smithsonian Design Museum

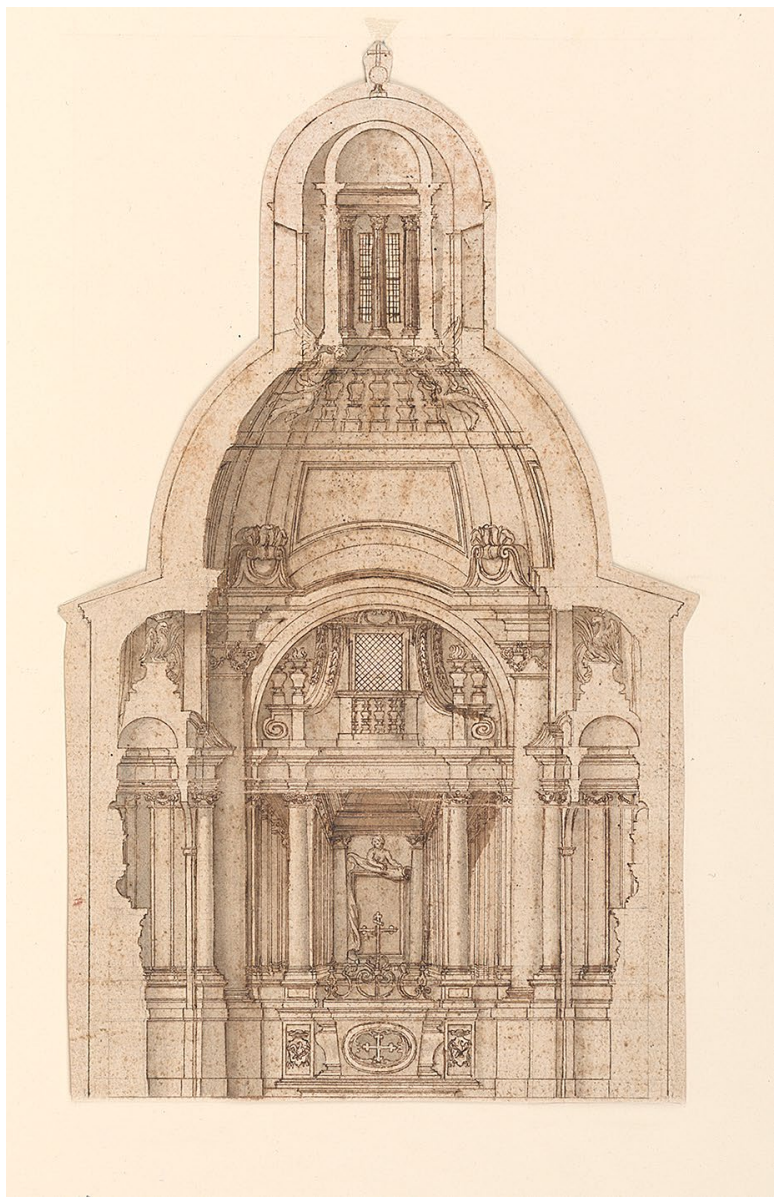

Among the emblematic and almost unknown examples of relief perspectives there is the Avila Chapel in Santa Maria in Trastevere realized in 1678 by the painter Antonio Gherardi. This was his first architectural project and he conceived it as an articulated space inspired by the works of the great Baroque masters Borromini and Bernini, in which sculpture, architecture and scenography are blended (Fig. 2). The chapel is set on a central plan with two lateral niches (the tombs) and the central altar, which constitutes a perspective system where the illusory space is contracted into a small real space. The sources of inspiration are Bernini's Scala Regia and Borromini's colonnade at Palazzo Spada. The latter may be considered a laboratory experiment in the manipulation of space, and Gherardi himself may have been motivated by the intention of being able to apply the same design approach in different contexts (Pickrel 1983). The altar is characterized by a direct and diffused lighting system generated by a dome (located at the centre of the altar) and by a smaller hemispherical cupola facing the painting of San Girolamo realized by Gherardi himself (Fig. 3). 

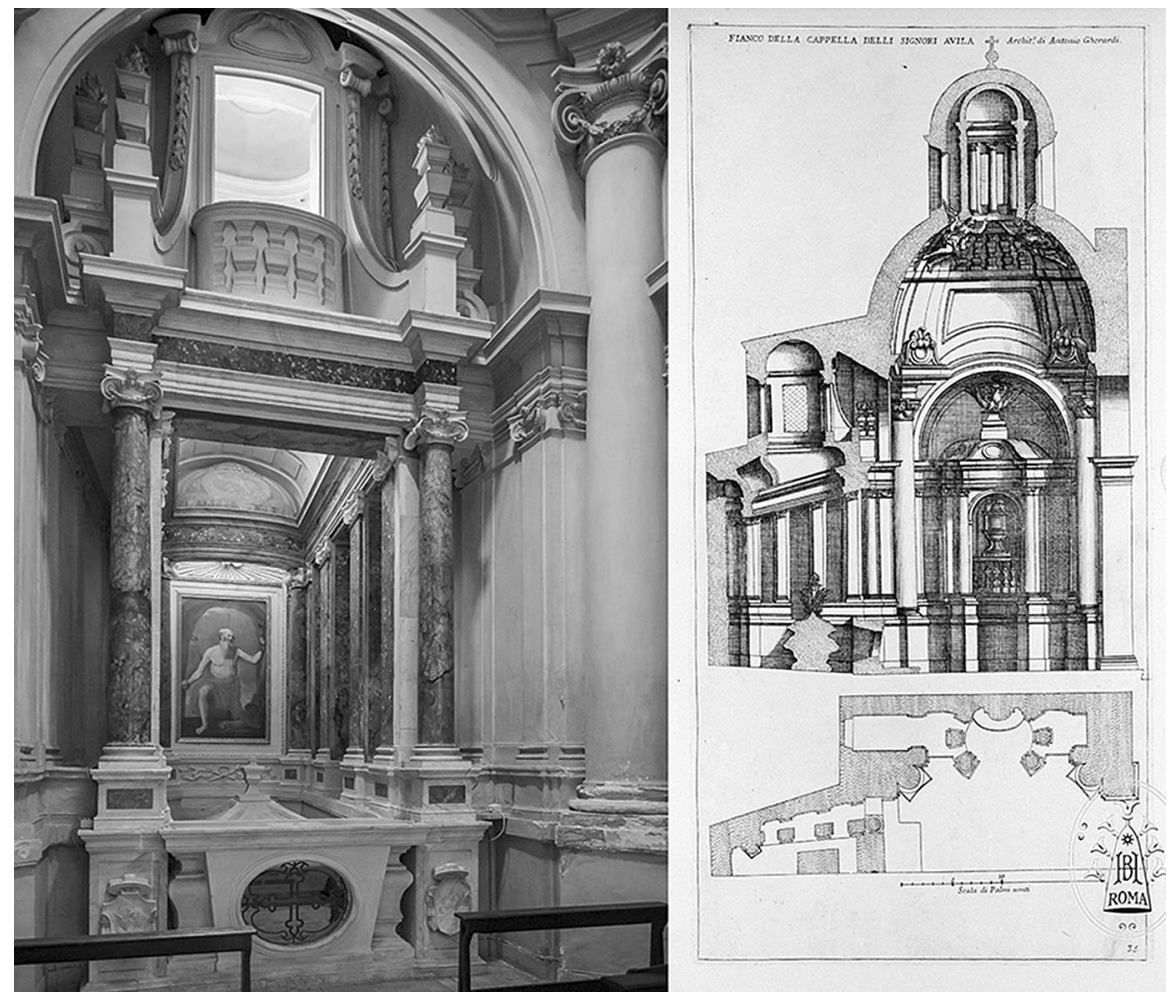

Fig. 3 The Avila Chapel and a section made by Giacomo De Rossi in 1713

\section{The Survey Model Phase}

The architectural survey was aimed at the metrical and morphological acquisition of the elements of the chapel with particular attention to the area of the altar (inaccessible) which is the subject of the perspective studies that follow. Despite the complexity of the architectural space, characterized by the wide and articulated movement of its surfaces, the acquisition was carried out by three main laser scanner stations. An accurate recording of the data generated a single point cloud from which it was possible to obtain a series of horizontal and vertical sections, which served for digital drawing. At the same time, a digital photogrammetry procedure was carried out. ${ }^{3}$ The textured model served for the detailed description of the Ionic capital in the front columns and in the gallery pilasters (Fig. 4).

The critical interpretation of the architectural survey was defined by a digital drawing carried out by means of the mathematical representation method to ensure

\footnotetext{
${ }^{3}$ The following equipment was used: Scanner Laser Leica C-10 and software Cyclone for the registration of point clouds; the sectional elevation and the horizontal sections were extracted with the same software; Nikon D800E, with $28 \mathrm{~mm}$ lens, for digital photogrammetry acquisition and Agisoft Photoscan for elaborating the textured model.
} 
Fig. 4 Point clouds sections

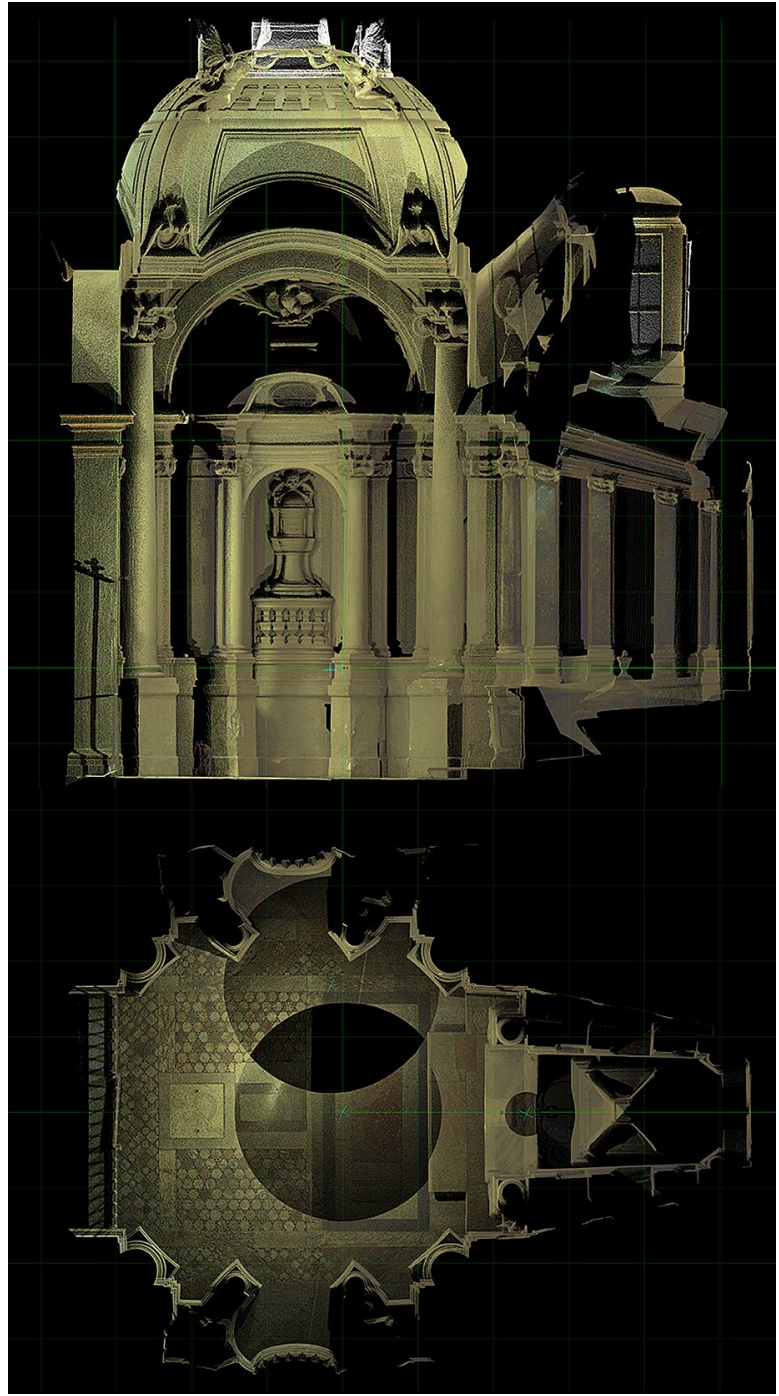

the metric control of entities, the description of their morphogenesis, and to support the geometric interpretation of the model (Fig. 5).

It is worth remembering that the survey model represents only one of the infinite possible relief perspectives of the illusory space, exactly like a frame of a movie that seamlessly transitions from the real space (affine) to the scenic space (projective).

This phase highlighted some peculiarities of Antonio Gherardi's project. The most important of these concerns the lack of convergence of some edges of the illusory 
Fig. 5 The mathematical model of the Survey Model with the collineation plane
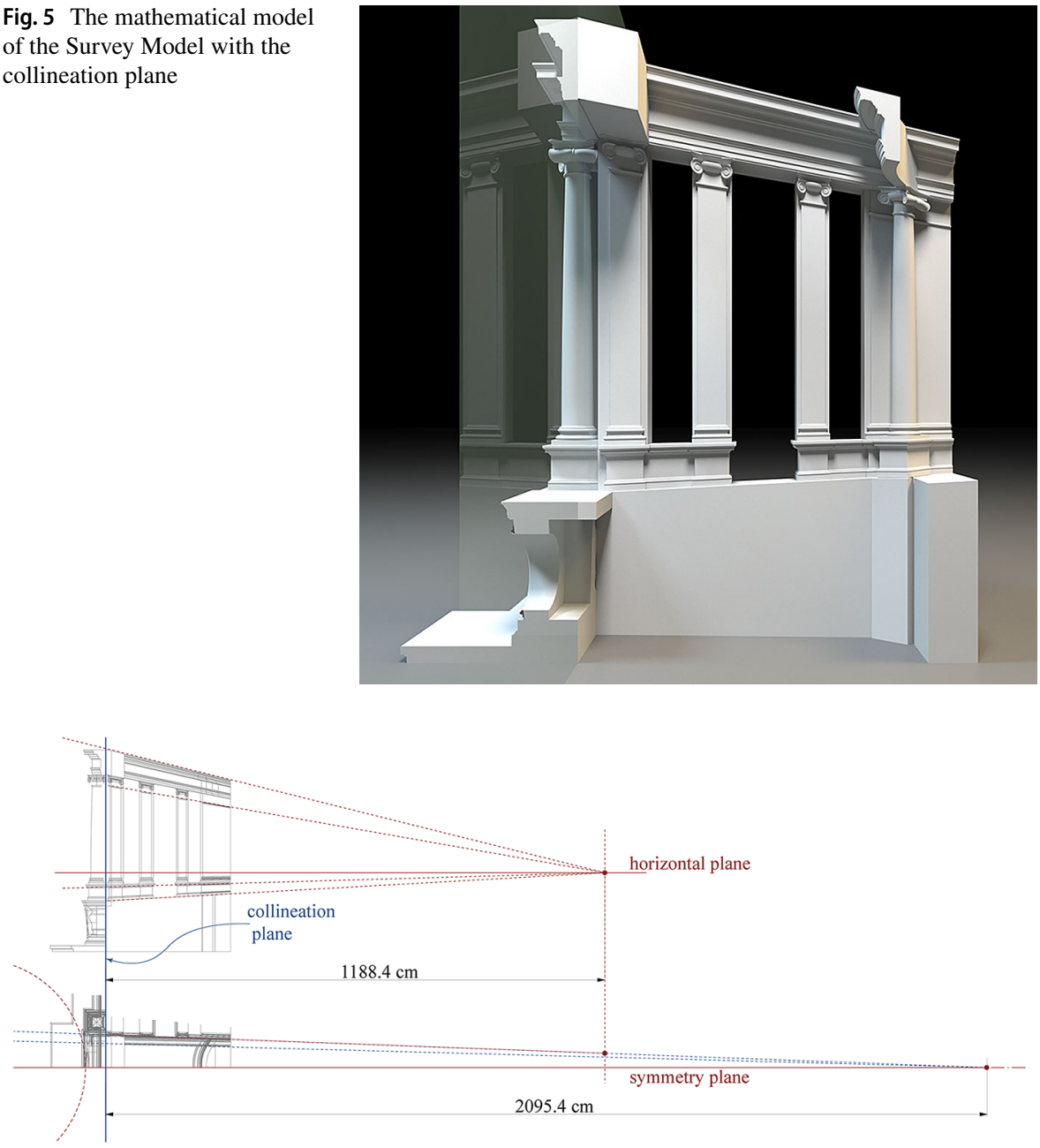

Fig. 6 Inconsistencies of vanishing points

space, which theoretically must meet in a single vanishing point of straight lines perpendicular to the front of the altar. In fact, in relief perspective, just as in linear perspective, parallel lines must have the same vanishing point. This problem is not perceived by direct observation of the gallery, which continues to be effective in its illusion but is only visible by comparing the longitudinal section of the altar with its plan view. We will propose an interpretation of this particularity, but the vanishing point is the principal aspect to consider for elaborating the restitution of the illusory space. Priority is given to the vanishing point inferable in the longitudinal section, in which we can observe that the pilasters are structured to consider the degradation of the apparent magnitudes (Fig. 6) and to highlight some aspects of the architectural structure of the altar. The truncated pyramidal space refers to a parallelepiped space 
characterized by two planes of symmetry, both vertical: the first is longitudinal and coincides with the real chapel; the second one is transverse, inside the perspectival gallery, and is indicated by a greater distance between the central pilasters.

Due to the absence of an obvious perspectival structure, the inverse transformation of relief perspective was based on an experimental and heuristic approach through the RPC defined by generative modelling systems.

\section{The Relief Perspective Camera (RPC)}

During and after the Renaissance many artists used mirrors and perspective machines to construct their drawings and to control the representation of space. Mirrors, or rather burnished and polished silver plates, were used to experimentally observe the form of the perspective images. In this way the images of the straight lines perpendicular to the picture plane were seen to converge in the reflection of the observer's eye (Camerota 2006; Baglioni and Migliari 2018).

Even if renaissance artists knew to construct linear perspectives in rigorous way (we can mention the treatise De prospective Pingendi by Piero della Francesca to testimony their scientific knowledge at the time, Field 2005) they often made use of perspective cameras. These tools were intended both for the realization of complex shape configurations and for the validation of projective principles as evidenced by the repertoire of perspective cameras and pinholes descriptions, analyzed in the Ninth Part of Daniele Barbaro's treatise The practice of perspective of 1568 (Monteleone, 2020). They needed an instrument to control and create a correct illusionary space without using the theoretical principles every time. Those perspective cameras were very simple; the more sophisticated ones were the pinhole camera. Today to create a perspective view we have many powerful machines: there are digital cameras to visualize an existing object or computers to create an illusionary space. Any 3D CAD can automatically generate a perspective frame. The RPC is like a perspective camera of the past or, if you prefer, like the ones we have implemented in any CAD software, but it creates relief perspectives instead of simple linear perspectives. It allows us to obtain a more general perspective than the usual linear perspective: a perspective that is contained in a three-dimensional space rather than a two-dimensional plane. The RPC also allows us to observe in real time the relationship between the projective space and the affine space, that of regular solid geometry. The linear perspective can be classified as a special case of relief perspective.

We can use this tool to study and generate architectural space or stage effects. Also, it is interesting and stimulating to study the projective transformations of curves and surfaces, for example, how a one-sheeted hyperboloid can be transformed in a hyperbolic paraboloid (Fallavollita 2016).

Before explaining the RPC parameters, we would like to recall some elements of relief perspective. The RPC allows us to obtain a relief or linear perspective of an object in real time. We can transform an object from the affine space to the illusory space and vice versa from the illusory space to the related one. The affine or isotropic space is the Euclidean space. The illusory or anisotropic space is the 


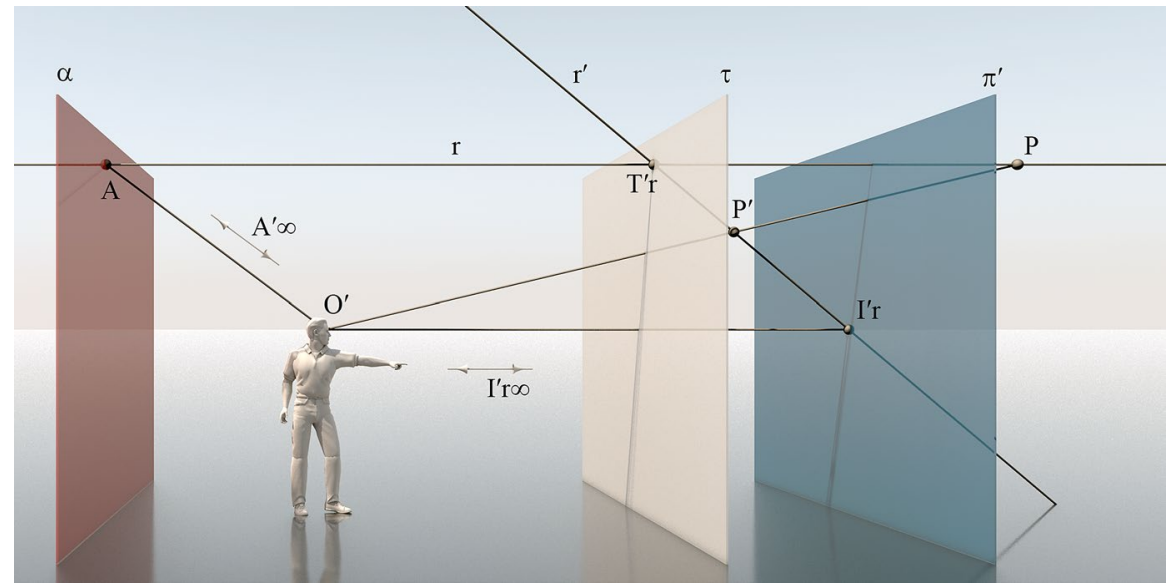

Fig. 7 The representation of the relief perspective of a straight line. The superposition of the affine isotropic space and the perspective anisotropic space

perspective space, which is two-dimensional in the case of the linear perspective and becomes three-dimensional in the case of the relief perspective.

In the perspective space there are some specific planes: the collineation plane, the vanishing plane and the anterior plane. The projection centre is the origin of the reference system. When the collineation plane and the vanishing plane coincide, that is they are superimposed, the camera returns a classical linear perspective. When we move the vanishing plane (or the collineation plane, it is possible to move both planes) the perspective from linear becomes relief: the illusory space overlaps the affine space.

By varying the distance between the collineation plane and the vanishing plane, the expansion or contraction of the perspective space is controlled. Furthermore, it is possible to move the object of investigation and bring it to the limits of the illusory and affine space: when an object that is in the affine space touches the anterior plane, it is sent into the illusory deep space and vice versa when an object that is in the illusory space touches the vanishing plane is sent into affine deep space.

The RPC's characteristic of being able to automatically control the perspective transformations both from the affine to the illusory space and from the illusory to the affine space has allowed us to construct the ideal model that the Baroque architect had imagined when he built the compressed space of the chapel.

To understand the functioning of the RPC we must imagine that the threedimensional object is projected from an affine space $\Sigma$ (the affine space) to an illusory space $\Sigma^{\prime}$ and vice versa. The two spaces are superimposed and infinitely extended.

In Fig. 7 we see an observer whose eye $\mathrm{O}^{\prime}$ is the projection centre of the relief perspective and also the centre of the coordinate system, a collineation plane $\tau$, a vanishing plane $\pi^{\prime}$ (or first limit plane), an anterior plane $\alpha$ (or second limit plane). The focal distance is $f$, i.e., the distance between the vanishing plane and the centre of projection. 


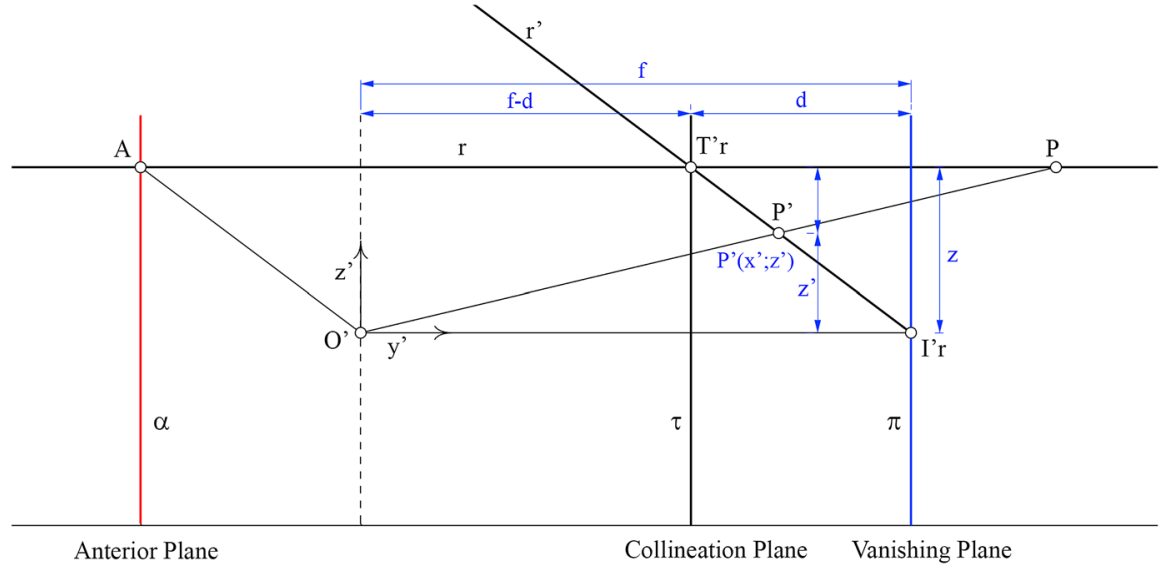

Fig. 8 The schematic view illustrating the reference system used to deduce the formulas of the Perspective Camera

We consider a straight line $r$ that belongs to the space $\Sigma$ and we project from the centre $\mathrm{O}^{\prime}$ to create the relief perspective. The line $\mathrm{r}$ meets the collineation plane at the point $T^{\prime} r$, the straight line. To construct the relief perspective line $r^{\prime}$ it is sufficient, as in the linear perspective, to draw a line parallel to the line $r$ through the centre of projection $\mathrm{O}^{\prime}$. This line will intersect $\pi^{\prime}$ at point $\mathrm{I}^{\prime} \mathrm{r}$, the vanishing point of the line. By combining the vanishing point I'r with the line $T^{\prime} r$ we obtain the relief perspective $\mathrm{r}^{\prime}$ that belongs to the scenic space.

A point $\mathrm{P}$ of the line $\mathrm{r}$, that belongs to the space $\Sigma$, has as its corresponding a point $\mathrm{P}^{\prime}$ of the line $\mathrm{r}^{\prime}$ belonging to the space $\Sigma^{\prime}$. If we consider the points of the line $\mathrm{r}$, in particular the point $\mathrm{A}$ and the point at infinity I, we can deduce that: the points at infinity such as I of the space $\Sigma$ correspond to the points $\mathrm{I}^{\prime}$ of the space $\Sigma^{\prime}$; while points such as A correspond to the point at infinity of the space $\Sigma^{\prime}$ such as $\mathrm{A}^{\prime}$.

These considerations allow to derive the mathematical formulas used in the RPC. In particular, the point $\mathrm{O}^{\prime}$ is the centre of the reference coordinate system. The $y$-axis is the depth while the $z$-axis is the vertical of the system. In Fig. 8 we see a section view of the aforementioned spatial configuration.

The RPC is based on some simple formulas (Migliari 2005):

$$
\begin{aligned}
& x^{\prime}=(f \times x) \div(d+y) \\
& y^{\prime}=(f \times y) \div(d+y) \\
& z^{\prime}=(f \times z) \div(d+y)
\end{aligned}
$$

The centre of the coordinate system is the projection centre of the RPC; $f$ is the focal distance, i.e., the distance between the centre of projection and the vanishing plane; $d$ is the distance between the collineation plane and the vanishing plane. Those formulas can transform the objects in the affine space in the new objects of the illusory space. Instead, the inverse transformation, i.e., from the illusory space into the affine space, is given by the other formulas: 


$$
\begin{aligned}
& x=\left(d \times x^{\prime}\right) \div\left(f-y^{\prime}\right) \\
& y=\left(d \times y^{\prime}\right) \div\left(f-y^{\prime}\right) \\
& z=\left(d \times z^{\prime}\right) \div\left(f-y^{\prime}\right)
\end{aligned}
$$

Therefore, the RPC can transform the objects in both directions: from affine space to illusory space and vice-versa.

The RPC can manage polylines and mesh surfaces. For that reason, before testing it we must transform the mathematical model into a numerical model. This tessellation process controls the accuracy of the numerical representation: the denser the tessellation, the more accurate the numerical model. In any case, the algorithm locates the mesh vertex points of the transformed model in a perfect manner without any approximations.

The RPC can automatically generate the transformed model and we can control in real time the parameters that generate the projective transformation. The RPC enables us to change the focal distance and the collineation distance in real time. The collineation distance allows us to dilate or contract the illusory, reducing the relief perspective to a simple linear perspective and vice versa. Furthermore, the RPC allows us to move the position of the object to be processed and, at the same time, allows us to observe the projective transformation.

As said, we can use this Camera to study relief perspective architecture or stage design effects.

The centre of the coordinate system is the projection centre of the RPC Camera. The parameters are:

1) three sliders controlling the position $(x, y$, and $z)$ of the model we want to transform;

2) a slider controlling the focal distance. This parameter controls the position of the vanishing plane, which is the plane containing the vanishing points;

3) a slider controlling the position of the collineation plane, which is the plane containing the lines connecting points.

The position of the second limit plane (or anterior plane) is determined by the position of both vanishing and collineation planes. The distance between the anterior plane and the centre of projection is equal to the distance between the vanishing plane and the collineation plane. For example (Fig. 9), if we want to obtain a linear perspective, we can move the second slider to the same value of the third or vice-versa. In this case, the vanishing plane and the collineation plane are superimposed, and the result is a two-dimensional model (linear perspective); consequently, the anterior plane is located exactly in the projection centre. Of course, if the object does not move the perspective view remains the same, despite the movement of the collineation plane and vanishing plane (Fig. 10).

With the help of these three parameters, we can control the infinite possibilities of the projective transformations. We can apply the RPC to study projective transformation of surfaces or curves and see what happens when we travel into deep space (Migliari 2005). Alternatively, as in this paper, we can study architecture and stage design effects. 


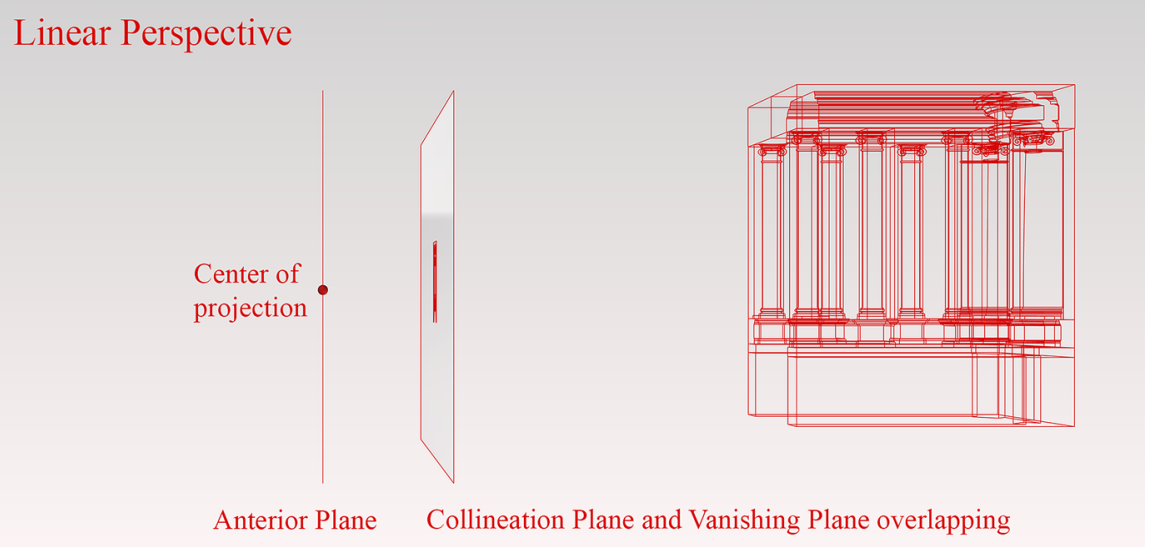

\section{Relief Perspective}

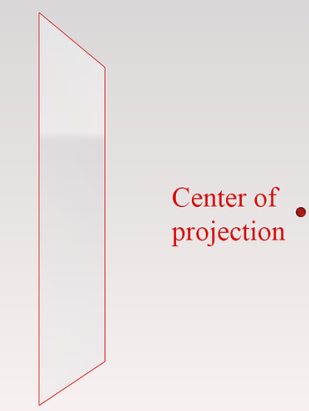

Anterior Plane

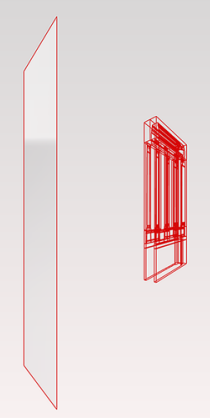

Collineation Plane

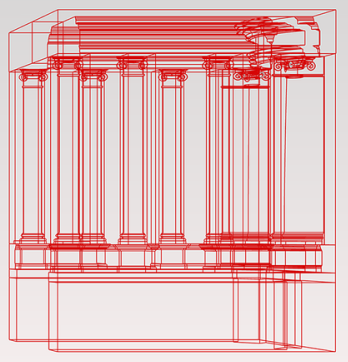

Vanishing Plane

Fig. 9 From linear perspective to relief perspective through Relief Perspective Camera

\section{The Projective Transformation Phase}

The first application in the Avila Chapel was to study the inverse transformation of the survey model: which is the transformation that goes from the projective space into the affine ones. The main goal was to find the ideal position of the projection centre in the Avila Chapel and consequently the illusory model of the Chapel. This model is the architectural model that the architect wanted to refer to; in other words, the affine space evoked by the contracted illusory space. To find the ideal solution we had to work in a tentative program. The heuristic approach was influenced by two fixed conditions. The first regards the position of the model in respect to the position of the collineation plane. The second is the distance between the collineation plane and the vanishing plane. We decided to keep the collineation plane superimposed to the frontal plane of the altar in the survey model (Fig. 11). The collineation plane contains the points of both spaces. The projective transformations affect all the 
Fig. 10 The image from the point of view (restricted sight) remains unchanged in the relief and linear perspective

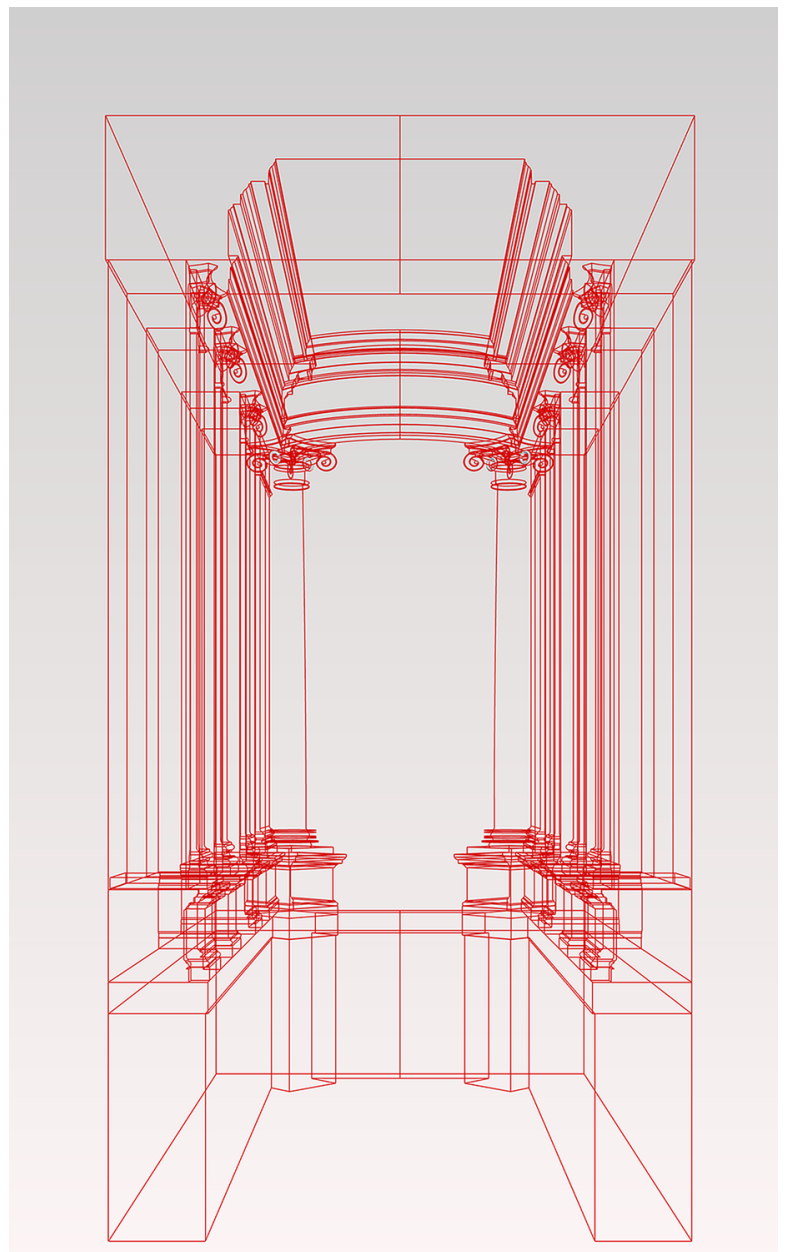

points of the affine space outside of the collineation plane. In this way, no matter what projective transformation is applied, both the front plane of the survey model and the frontal plane of the illusory model are always superimposed and equal.

The distance between the collineation plane and the vanishing plane was obtained through the analysis of the survey model. As we mentioned above, we decided to work on the longitudinal section of the Chapel because this elevation is more evident and visible than the plan. The lines of the cornices, which go in the same ideal direction, meet in a point that must lie on the vanishing plane. The collineation plane is fixed; so the distance between the first limit plane and the collineation plane is equal to $1188 \mathrm{~cm}$. With the two mentioned fixed parameters, the illusory model is determined only by the focal distance. The tentative program was to obtain the 


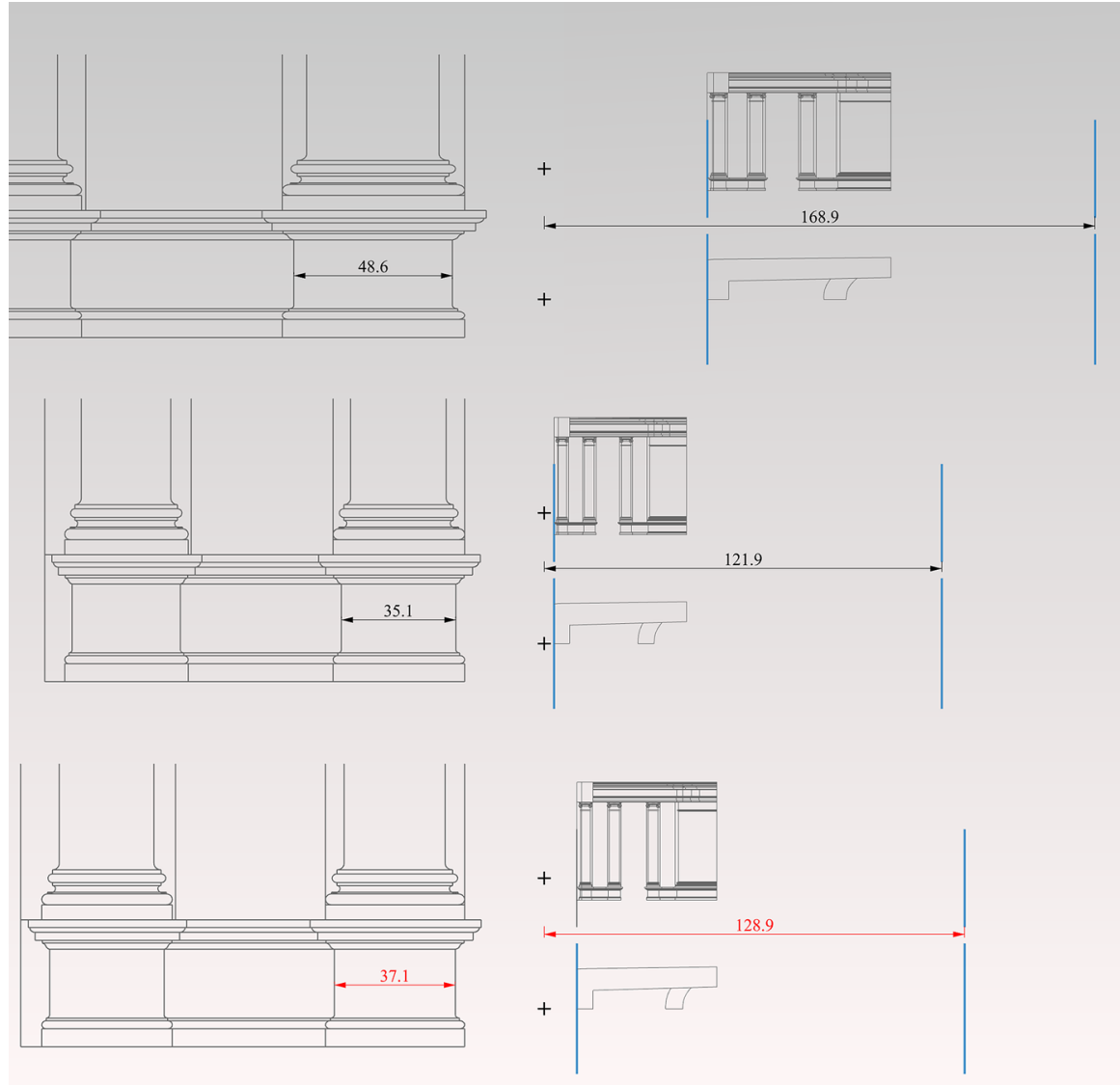

Fig. 11 The proportions of the Ideal Model

illusory model that has the widths of the basement pilasters equal to the widths of the front basement columns, which are in real dimensions.

In Fig. 11 we can see three different cases: obviously, the height is always the same, what changes is only the width in the $y$ direction. After some experiments, we found a more reasonable distance, i.e., the distance compatible with the measure of the transformed pilaster. This distance is close to $100 \mathrm{~cm}$ and is coherent with the architectural space of the chapel. In fact, a man standing $100 \mathrm{~cm}$ from the front plane of the chapel is positioned in the centre of the step-in front of the projective stage. This model in the longitudinal section looks perfectly regular, apart from the different widths of the pilasters. On the other side, as we expected, the plan view of the ideal model looks slightly distorted: it tends to open. This problem is because the plan and the elevation are not perfectly coherent with the projective centre. 


\section{The Ideal Model and the Comparison Phases}

The ideal model is the mathematical representation of the illusory space which Gherardi wanted to refer to. It derives from the study of the illusory model. In this way the ideal model respects all the architectural elements, regularity and proportions of the illusory rectangular space articulated by the pilasters (Fig. 12). The proportion of the illusory space is in a ratio 1.5:1 which is a credible feature in classical architecture. At the end of the room, there are two columns which sustain the hemispherical dome, equal to the ones in the front but rotated by $45^{\circ}$. The ideal model is then transformed through the RPC, bringing it from the affine space to the contracted projective space of the altar. Only the direct comparison between the relief perspective of the ideal model with the survey model shows some interesting differences (Fig. 13). The first can be traced on the dissimilar degradation of apparent magnitudes of the pilasters. The second, most important, is the convergence of the lines of the mouldings in two vanishing points rather than one, as can be seen in the ideal model. The thing that stands out by observing the two perspective views is the different width of the two architectural spaces: the ideal model is narrower than the survey model (Fig. 14).

This apparent inconsistency was probably intentionally designed by Gherardi. The larger, distorted space better hosts the painting of San Girolamo, the main theme of the altar. Besides these observations we should notice that the visual perception of the altar, even with these exceptions of the rules of perspective, is still effective in its illusion. The reason can be found in visual perception. To our eyes, the architecture appears to support the laws of perspective "as it looks"- to quote Arnheim (1977: 110)_but to our mind, it appears in its solid formal regularity "as it is". When we observe a relief perspective that simulates the depth of an architectural space, inevitably the visual perception (perspective) is activated and so is the mental perception of the space (orthographic), the dialogue between them develops continuous interpretations. The space of the Avila Chapel is a typical Baroque space characterized by dynamic and complex surfaces in which it is impossible to distinguish between sculpture and architecture. The altar and its relief perspective (even with all the mentioned incoherencies) is the only affine, classical space of the chapel where our mind can find peace and see it as regular architecture.

\section{Conclusions}

The main purpose of this research is to propose a working methodology for the study of relief perspectives, especially architectural ones. The idea is to use the virtual laboratory as a digital environment for experimentation with space and models. We have seen how it is possible to use a RPC. This tool has been designed in a mathematical modeller and is based on the geometric principles of projective theory. We have translated the theoretical and practical principles of perspective construction into algorithms to generate relief perspective views mechanically and automatically. Once we tested its accuracy and functioning, we decided to apply it to real cases. 
Fig. 12 Comparison between the Survey Model (above) and the transformed Ideal Model (bottom)

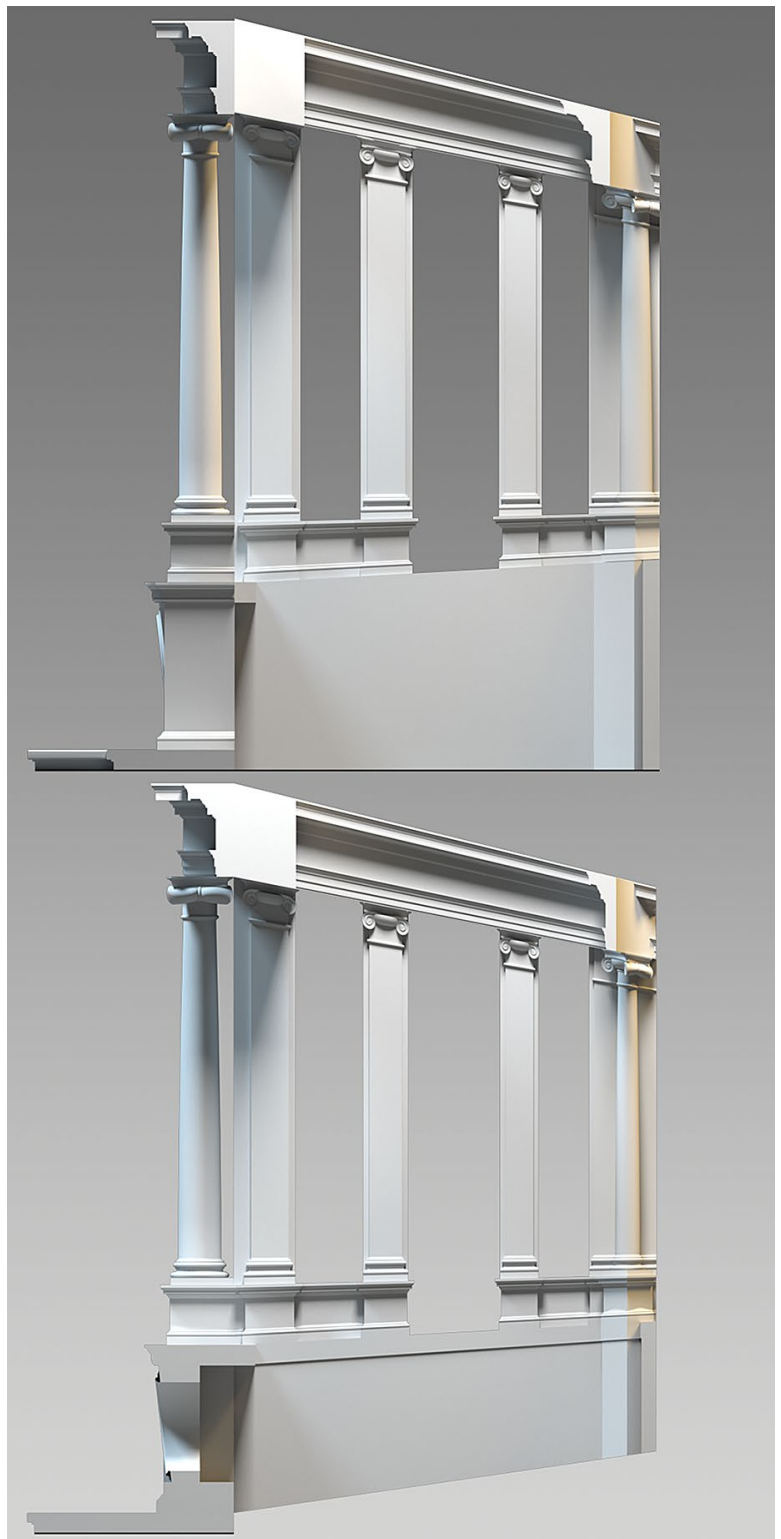

In the methodology illustrated, reference is made to different models: the survey model, the draft model and the ideal model. It is important to remember that any representation of reality, be it analogical or digital, is always a model and will never be the objective reality. This simple observation is even more true if we think about drawings of unrealized or lost projects. The construction of a model, therefore, is always an interpretative operation of an idea or a reality and it will always carry the cultural imprint of both its time and those who created it. This is also true in the 


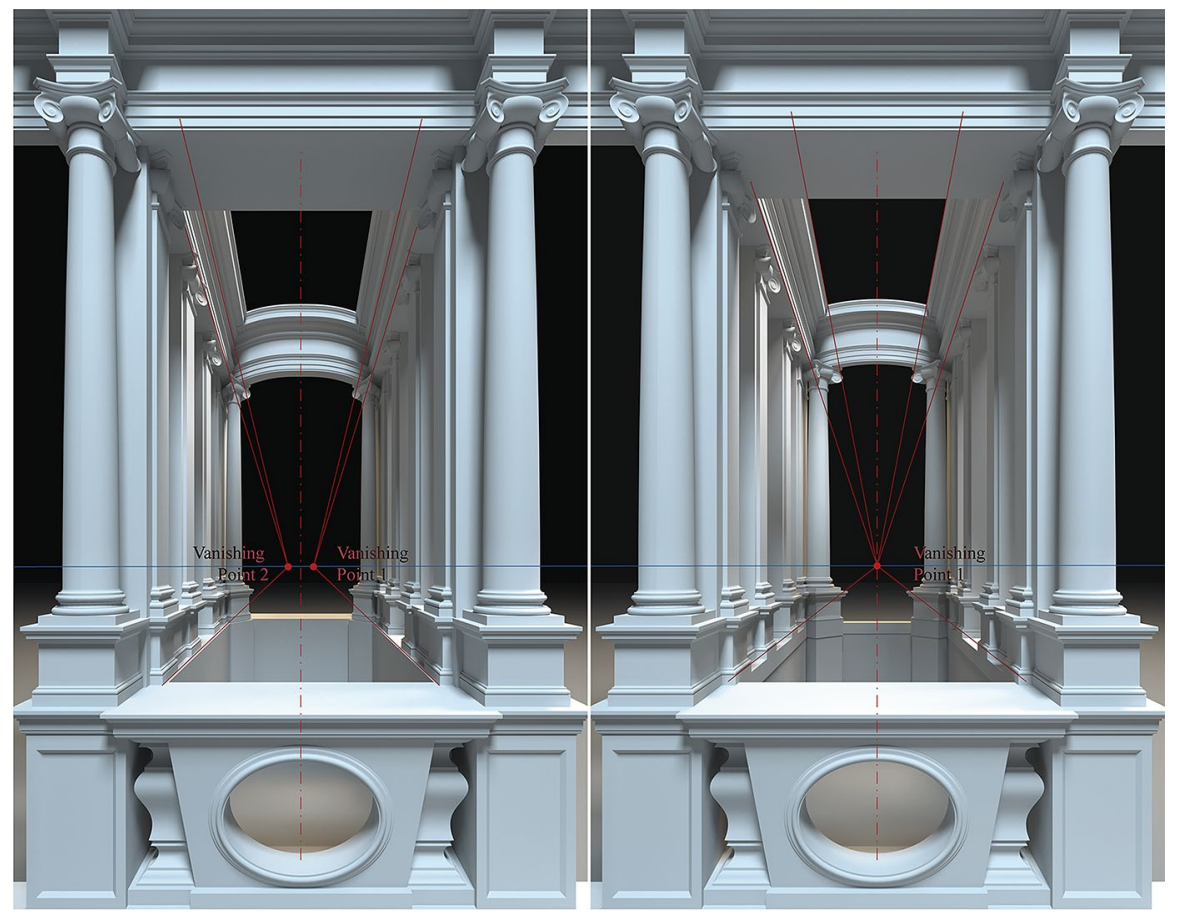

Fig. 13 Comparison between the Survey Model (left) and the transformed Ideal Model (right) from the projection center

case of an architectural survey operation: the survey drawing is the representation of a model that would like to objectively describe an existing reality but remains an interpretative model (Docci and Maestri 2010: 4-14).

Digital representation has enhanced the ability to explore different model ideas. In this specific case, for example, the possibility of automatically generating relief perspectives made it possible to research and find the ideal reference model of the perspective space. This research would similarly have been carried out with analogical instruments, but the timing and results would not have been as fast and accurate as today.

It is important to underline that a digital algorithm camera such as the RPC can only be drawn starting from a deep knowledge of the projective principles at the basis of a phenomenon, in our case that of relief perspective. This awareness can guarantee the critical control necessary for a correct interpretative analysis of the processed data, highlighting anomalies, inconsistencies, and exceptions (conscious or not) to the rules of perspective. The possibility of interacting in real time with the transformations of the projective space, being able to observe the entire system from multiple points of view ("as it looks" and "as it is"), considerably increases the heuristic power of drawing and provides inspiration for possible future developments. In the case study of the Avila Chapel, for example, the proposed research has highlighted the hidden characteristics of Gherardi's 


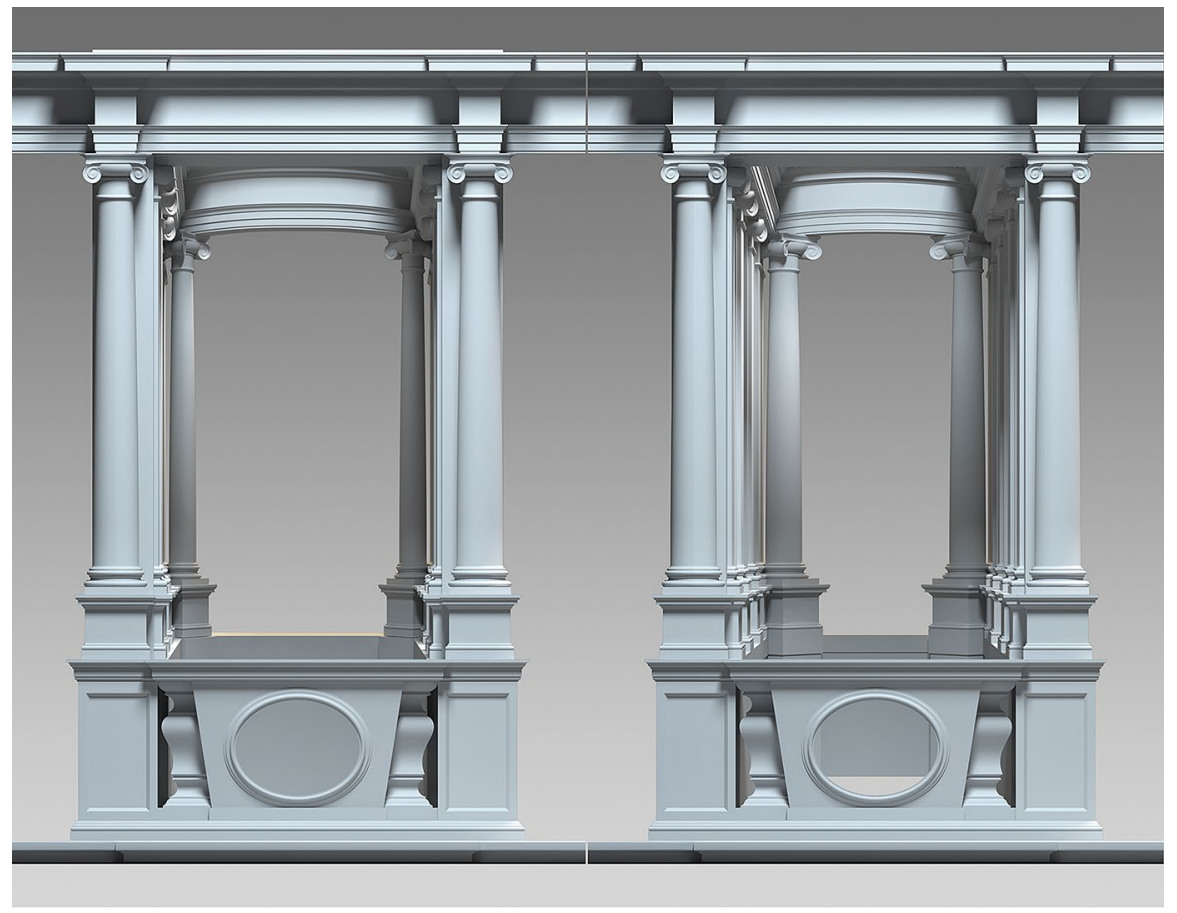

Fig. 14 Comparison between frontal elevations of the Survey Model (left) and the transformed Ideal Model (right). Note that the orthogonal projection of a relief perspective is a linear perspective

project, which stands as a skilful synthesis between the scientific precision of the perspective system and its exceptions resulting from his artistic criteria as a sculptor who shapes space with sensitivity and mastery. We have described the results of his choices; we have been able to evaluate the metrical aspects and finally we have proposed the design logic. But there is still much to be done to investigate the operating method used for its realization, which could tell us a lot about the perspective knowledge of that time. This operating practice (stage design) would eventually evolve two centuries later into a mathematical science (projective geometry).

Today the ability to almost automatically experience and experiment with complex relief perspectives makes it possible to study and read these architectures under new lenses. In the future, therefore, we would like to apply this methodology to other case studies to rediscover a heritage that is not well known, as in the Avila Chapel case, but at the same time is particularly significant for the history of representation. Relief perspective depicts a close connection between the theoretical evolution of perspective, intended as science, and its application to art, stage design and architecture.

Acknowledgements All images are by the authors unless otherwise noted. Author contributions: Leonardo Baglioni and Federico Fallavollita completely shared the methodology and the content of the 
research. Leonardo Baglioni, in addition, deepened the historical framework of relief perspective and the construction of the ideal model. Federico Fallavollita, in addition, deepened the construction of the Relief Perspective Camera.

Funding Open access funding provided by Università degli Studi di Roma La Sapienza within the CRUICARE Agreement.

Open Access This article is licensed under a Creative Commons Attribution 4.0 International License, which permits use, sharing, adaptation, distribution and reproduction in any medium or format, as long as you give appropriate credit to the original author(s) and the source, provide a link to the Creative Commons licence, and indicate if changes were made. The images or other third party material in this article are included in the article's Creative Commons licence, unless indicated otherwise in a credit line to the material. If material is not included in the article's Creative Commons licence and your intended use is not permitted by statutory regulation or exceeds the permitted use, you will need to obtain permission directly from the copyright holder. To view a copy of this licence, visit http://creativeco mmons.org/licenses/by/4.0/.

\section{References}

Andersen, Kirsti. 2007. The Geometry of an Art. New York: Springer.

Arnheim, Rudolf. 1977. The Dynamics of Architectural Form. Berkeley: University of California Press.

Aschieri, Ferdinando. 1887. Geometria descrittiva. Milano: Ulrico Hoepli.

Baglioni, Leonardo and Riccardo Migliari. 2018. The mirror at the origin of perspective. Disegnare, idee immagini 56: 42-51.

Baglioni, Leonardo and Marta Salvatore. 2018. The Points of Concurrence Theory in Guidobaldo del Monte's Scenography. Diségno. https://doi.org/10.26375/disegno.3.2018.6

Camerota, Filippo. 2001. La scena teatrale. In Nel segno di Massaccio, ed. Filippo Camerota, 149-164. Firenze: Giunti.

Camerota, Filippo. 2006. La prospettiva del Rinascimento. Arte, architettura, scienza. Milano: Mondadori Electa.

Del Monte, Guidobaldo. 1600. Perspectivae Libri sex. Pesaro: Girolamo Concordia.

Docci, Mario and Diego Maestri. 2010. Manuale di rilevamento architettonico e urbano. Edizione Laterza.

Fallavollita, Federico. 2016. The connection between projective space and affine space and the solid perspective machine. 17th international conference on geometry and graphics, Beijing, China.

Fiedler, Wilhelm. 1874. Trattato di geometria descrittiva. Firenze: Le Monnier.

Field, Judith Veronica. 2005. Piero Della Francesca: A Mathematician's Art. Yale University Press.

Leopold, Cornelie. 2019. The Development of the Geometric Concept of Relief Perspective. Nexus Network Journal 21: 227-252.

Migliari, Riccardo. 2005. Ha la prospettiva un futuro? (has man a future?). In: Ikhnos, Analisi Grafica e Storia della Rappresentazione, 133-160. Siracusa: Lombardi Editori.

Monteleone, Cosimo. 2020. La prospettiva di Daniele Barbaro. Note critiche e trascrizione del manoscritto It. IV, 39=5446. Roma: Aracne Editrice.

Pickrel, Thomas C. 1983. Antonio Gherardi: painter and architect of the late baroque in Rome. Lawrence: University of Kansas.

Poncelet, Victor. 1822. Traité des propriétés projectives des figures, ouvrage utile a ceux qui s'occupent des applications de la géométrie descriptive et d'opérations géométriques sur le terrain. Paris: Bachelier.

Steadman, Philip. 2020. Baldassare Peruzzi and Theatrical Scenery in Accelerated Perspective. Nexus Network Journal 22: 553-576.

Tedeschi, Arturo. 2014. AAD_Algorithms Aided Design. Potenza, Italy: Le Penseur.

Publisher's Note Springer Nature remains neutral with regard to jurisdictional claims in published maps and institutional affiliations. 
Leonardo Baglioni Architect and $\mathrm{PhD}$, is Associate Professor for the scientific discipline ICAR/17 at Sapienza University of Rome, where he teaches in the courses of Drawing and Fundamentals and Applications of Descriptive Geometry in the Faculty of Architecture. Since 2017 he has been the scientific coordinator of the Laboratory of Innovation for the Detection, Representation and Analysis of Architecture (LIRALab) in the Department of History, Representation and Restoration of Architecture. His research is mainly focused on descriptive geometry, its history and its applications, with particular interest in its renewal by means of digital representation methods. In 2006 and 2007 he was part of the interdisciplinary research group for the publication of the National Critical Edition of the treatise "De prospectiva pingendi" by Piero della Francesca, promoted in 2010 by the Piero della Francesca Foundation.

Federico Fallavollita is Associate Professor at the Department of Architecture of University of Bologna, where he teaches courses of drawing at the single cycle degree/combined bachelor and master in Architecture and first cycle degree Bachelor in Industrial Design. He graduated with honors in architecture from Sapienza University of Rome. In 2008 he obtained a PhD in Sciences of Representation and Survey at the Department of History, Design and Restoration of Architecture at Sapienza University of Rome with a thesis entitled "The ruled surfaces and developable surfaces, a reading through the virtual lab". He deals with the issues of representation and survey of architecture. He is mainly interested in renewal of descriptive geometry through the new informatics tools. His research also focuses on the hypothetical virtual reconstruction of architecture never built or lost. 